Milne E, Greenop K, Fritschi L, Attia J, Bailey H, Scott RJ et al. (2014). Childhood and parental diagnostic radiological procedures and risk of childhood brain tumors. Cancer Causes \& Control, 25(3), 375-383.

(C) Springer International Publishing Switzerland 2014

This is pre-copy-editing, author-produced version of an article accepted for publication in Cancer Causes and Control, following peer review. The final publication is available at Springer via http://dx.doi.org/10.1007/s10552-014-0338-x

This version was made available in the UWA Research Repository on the $19^{\text {th }}$ of March 2015 , in compliance with the publisher's policies on archiving in institutional repositories.

Use of the article is subject to copyright law. 


\section{Childhood and Parental Diagnostic Radiological Procedures and risk of Childhood Brain Tumors}

Authors: Elizabeth Milne ${ }^{1}$, Kathryn R. Greenop ${ }^{1}$, Lin Fritschi ${ }^{2}$, John Attia ${ }^{3,4}$, Helen D. Bailey ${ }^{1,5}$, Rodney J. Scott ${ }^{4,6,7}$, Lesley J. Ashton ${ }^{8}$, Elizabeth Smibert ${ }^{9}$, Bruce K. Armstrong ${ }^{10}$.

Author Affiliations:

1. Telethon Institute for Child Health Research, University of Western Australia, Perth, Western Australia, Australia.

2. Western Australian Institute for Medical Research, University of Western Australia, Perth, Western Australia, Australia

3. School of Medicine and Public Health, Faculty of Health, University of Newcastle, Newcastle, New South Wales, Australia

4. Hunter Medical Research Institute, John Hunter Hospital, New South Wales, Australia.

5. Section of Environment and Radiation, International Agency for Research on Cancer, Lyon, France.

6. School of Biomedical Sciences and Pharmacy, Faculty of Health, University of Newcastle, Newcastle, New South Wales, Australia.

7. Hunter Area Pathology Service, HNEHealth, Newcastle, New South Wales, Australia.

8. Children's Cancer Institute Australia for Medical Research, Lowy Cancer Research Centre, University of New South Wales, Sydney, NSW, Australia.

9. Children’s Cancer Centre, Royal Children’s Hospital, Parkville, Victoria, Australia.

10. Sydney School of Public Health, University of Sydney, Sydney, New South Wales, Australia

Author for correspondence:

Dr Elizabeth Milne

Telethon Institute for Child Health Research

PO Box 855 West Perth, Western Australia 6872, Australia

Telephone: +610894897756

Facsimile: +61 0894897700

Email: lizm@ichr.uwa.edu.au 


\section{Abstract \\ Purpose}

Childhood brain tumors (CBT) are the second most common type of childhood cancer and the leading cause of childhood cancer mortality. Few causes of CBT are known, but parental, fetal and early life exposures are likely to be important given the early age at diagnosis of many cases. We aimed to investigate whether parent's diagnostic radiological procedures before conception, in the mother during pregnancy or the child's procedures were associated with an increased risk of CBT.

Methods

This population-based case-control study was conducted between 2005 and 2010. Cases were identified through all ten Australian pediatric oncology centers, and controls via nationwide random-digit dialing; frequency-matched to cases on age, sex and state of residence. Information on radiological exposures in the time periods of interest was obtained for 306 case and 950 control families through mailed questionnaires. Analysis used unconditional logistic regression, adjusting for matching variables and potential confounders.

Results

We found no evidence of positive associations between risk of CBT overall and childhood or parental pre-pregnancy radiological procedures. Elevated ORs for high grade gliomas associated with childhood radiological procedures were based on small numbers and may be due to chance. Conclusions

Given the evidence for an increased risk of CBT in cohort studies of CT (computed tomography) in childhood, the lack of such an association in our study may be due to the reduced intensity of CTs after 2001. Future research to investigate the safety of fetal exposure to more intense procedures like CT scans is needed.

Keywords: X-rays, child, central nervous system, neoplasms, medical imaging, case-control study, CT scans 
Introduction

Childhood brain tumors (CBT) are the second most common type of childhood cancer after acute leukemia, and are associated with a high rate of morbidity and mortality. The known causes of CBT are limited to exposure to ionising radiation in childhood and a few specific genetic syndromes which account for less than 5\% of cases [1]. Many cases of CBT occur in early childhood, indicating that some predisposing or initiating events may occur before conception, during fetal life or in infancy.

The International Agency for Research on Cancer has stated that there is sufficient evidence for the carcinogenicity of X-radiation in humans, including "substantial evidence that suggests a causal association between exposure to diagnostic radiation in utero and childhood cancers” (p168) [2]. Ionising radiation has been shown to increase the risk of brain tumors among children treated for tinea capitis or hemangioma [3]. Children and fetuses may be more susceptible to the DNAdamaging effects of radiation than adults, because of the high rate of cellular proliferation [4].

Two recent cohort studies of exposure to computerised tomography (CT) in childhood and/or early adulthood reported positive associations for brain tumor risk, after follow-up of up to 23 years [5,6]. In both studies, the increased risks were highest after CTs of the brain and, in the Australian study, for CTs done at younger ages and closer to the time of diagnosis (after excluding a 'lag period') [6]. Another smaller cohort study with maximum follow-up to age 15 reported an OR of 0.52 (95\% CI $0.25,0.95)$ for any radiological procedure in childhood; only $3.7 \%$ of procedures were CT scans [7].

Among case-control studies of childhood radiological exposure and CBT, three reported little evidence of associations,[8-10] while four others reported at least weak evidence of positive associations, with ORs of 1.5 (95\% CI 0.8, 3.0) [11], 1.5 (95\% CI 0.7, 3.3) [12], 2.2 (95\% CI 0.6, 8.8) [13], and 2.3 (95\% CI 0.91, 5.7) for primitive neuroectodermal tumors (PNETs) after cranial $\mathrm{X}$-rays for reasons other than head injury [14].

As described in two recent reviews $[15,16]$, most studies of maternal radiological procedures during pregnancy and risk of CBT have reported null results, consistent with studies published since these reviews $[7,10]$. Only one study of gestational procedures reported an increased risk, and this was observed for PNET only [17]. The only previous study we identified of parental preconception radiological exposures reported no increased risk for procedures carried out on either parent [11]. The Australian Study of Childhood Brain Tumors (Aus-CBT) was a nationwide case-control study designed to investigate environmental and genetic risk factors for CBT. The aim of the current analysis was to determine whether diagnostic radiological procedures in the parents or the child 
were associated with an increased risk. We specifically aimed to investigate whether any such association varied by period of exposure and procedure type (and by inference, dose).

To our knowledge, this is the first epidemiological study to investigate risk of CBT in relation to parental preconception, fetal and postnatal exposure to specific types of radiological procedures.

Methods

Details of the design and recruitment methods for Aus-CBT have been described previously [18]. Briefly, incident cases of CBT diagnosed between 2005 and 2010 were identified through all 10 pediatric oncology centers in Australia. Where deemed appropriate, the treating clinician invited the parents to participate in the study as soon as possible after diagnosis. Controls were recruited by national random digit dialling (RDD) and frequency matched to cases by age (within 1 year), sex and state of residence in a ratio of 3:1. Controls recruited in 2007 - 2010 were frequency matched to incident CBT cases, while those recruited in 2005 and 2006 had been frequency matched to cases in our concurrent study of childhood acute lymphoblastic leukemia (Aus-ALL; 2003-2007); the studies used identical RDD recruitment methods [19].

Cases and controls were eligible for inclusion if they resided in Australia and had a biological parent who could complete questionnaires in English. Both studies were approved by the Human Research Ethics Committees at all participating hospitals.

As soon as consent was received, parents were mailed questionnaires requesting detailed information about demographics and relevant exposures, including radiological procedures. Mothers were asked whether the child had undergone any 'X-rays' before their diagnosis (for cases) and since birth (for controls). Requested details included the body part/s examined: 'Head (including dental)', 'Chest', 'Abdomen (including stomach/hips)', 'Arm(s)', 'Legs(s)', 'Whole body'; and procedure type: 'Plain X-ray', ‘CAT scan (CT scan)', 'IVP (kidney)’ (intravenous pyelogram), 'Barium study', 'other'. The child's age at the time of the procedure was requested in years and months. The reason for the procedure was not ascertained.

Both parents were asked whether they had undergone any radiological procedures before the child was born, and the body parts involved: 'Pelvis', 'Hips', 'Lower back', 'Abdomen (including stomach)', 'Kidneys'; the scan type (options as above), and the age in years when the procedure took place. The body areas chosen were designed to obtain information about procedures that could potentially affect the reproductive organs in the parents, or the fetus in utero. The information provided also enabled exclusion of non-radiological procedures (e.g. MRI, ultrasound) from the analyses. 
As previously described, we also had an area-of-residence-based measure of socio-economic status (SES) for each family who agreed to take part in the study, the Index of relative socioeconomic disadvantage [18].

\section{Exposure Metrics}

Radiological procedures undertaken on the mother or father at any time before the index pregnancy were identified from the questionnaire data. Maternal procedures during the pregnancy and paternal procedures during the two years leading up to the conception of the index child were also identified; paternal procedures after the conception date were excluded. Child exposures were limited to procedures that occurred more than six months before the censoring date (the age at diagnosis for cases and the age at questionnaire return for controls), in an attempt to exclude procedures that may have been related to early symptoms of CBT. Sensitivity analyses using 12-month and five-year lag periods were also performed.

\section{Statistical Procedures}

Odds ratios and 95\% CIs were estimated using unconditional logistic regression in PASW Statistics for Windows Version 18.0 (SPSS Inc., Chicago, 2009). The matching variables (child's age, sex and State of residence) were included in all analytical models. The following variables were investigated as potential confounders as they have been previously reported, by us or others, to be associated with CBT risk, participation or the exposures under investigation: child's birth year, diagnosis/recruitment year, child's ethnicity, parental age, parental alcohol use, parental smoking, maternal pre-pregnancy folate supplementation, parental education, household income and area based SES. Variables assessed by visual comparison of distributions as associated both with case/control status and with exposure among controls were included in the models (erring on the side of inclusion). Different covariates were included in the models of the child's and parents' radiological exposures, as different variables met the criteria for confounding in each. The covariates included in final statistical models are listed in the footnotes to Tables 2 and 3. Linear trends were tested for with a Wald test for ordinal categorical variables entered into models with 1 degree of freedom.

Results

Full recruitment details and participation rates have been published previously [18]. Briefly, 730 eligible CBT cases diagnosed between 2005 and 2010 were identified, 568 of whom were invited to participate by their treating physician; the physician opted not to invite the remaining 162 cases for medical or psychosocial reasons. Parents of 374 cases consented to participate (65.8\% of invited, $51.2 \%$ of eligible). The age and sex distributions among invited and uninvited cases were similar: mean age 6.9 versus 6.1 (respectively), and 58.3\% versus 55.6\% were boys (respectively). 
Similarly, the age and sex distributions among cases who consented and those who did not were: mean age 6.8 versus 7.2 (respectively), and 58.6\% versus $57.7 \%$ were boys (respectively).

In the same time period, 3,624 eligible control children were identified by RDD, of whom 2,255 (62.2\%) agreed to participate; in accordance with our frequency-matching quotas, 1,467 children were recruited. For ethical reasons, no information was available about potential controls that declined to participate.

Information on radiological procedures was provided via questionnaire by 302 case mothers (81\% of those recruited), 247 case fathers (66\% of recruited), 941 control mothers (61\% of recruited) and 801 control fathers (55\% of recruited). The distributions of child’s age and sex were similar among questionnaire completers and non-completers. Among both cases and controls, however, completers had higher area-based SES scores than non-completers $(\mathrm{p}<0.01)$ and, in cases but not controls, completers were born 2 years earlier, on average, than non-completers $(\mathrm{p}<0.01)$.

The demographic characteristics of families who had returned any written questionnaire are shown in Table 1. Because controls for cases diagnosed in 2005 and 2006 had been matched to cases from our study of ALL, there were proportionally more female controls and fewer controls aged over 10 years, compared with case children. Controls were more likely than cases to be recruited in 20052006, have older and more highly educated parents, and be of European ethnicity.

The OR for having any diagnostic radiological procedures during childhood was 0.66 (95\% CI: 0.48, 0.90), with an apparent inverse trend ( $\mathrm{p}$ for trend $=0.009$ ) (Table 2). The ORs for X-ray examinations, including those to the head or the chest, were below the null. The ORs for CT scans were also below the null, although they tended to be higher than those for X-rays and were less precise as a result of relatively small numbers. When the lag period between the last exposure and the censoring date was increased from six months to 12 months and five years, ORs for any radiological procedure during childhood changed little: 0.59 (95\% CI: 0.43, 0.83) and 0.61 (95\% CI: $0.39,0.97)$ respectively. Our findings did not vary by age at exposure (data not shown). There was little evidence of any interaction between parental or filial radiological procedures and age at diagnosis/recruitment (data not shown). The results for childhood exposures were fairly consistent across CBT subtypes, although the OR for any childhood radiological exposure and high grade glioma was 1.71 (95\% CI 0.68, 4.30) (Table 4). No case children and only 14 control children had a barium study, and only three cases and 14 controls had an IVP (data not shown).

There was essentially no evidence of any increased risk of CBT associated with maternal or paternal exposure to radiological procedures at any time before the index pregnancy; in fact, the ORs for maternal pre-pregnancy exposures were all below the null, with an apparent inverse trend (Table 3). The ORs for paternal exposure were all close to the null: 0.89 (95\% CI 0.64, 1.24) for 
any time prior to conception (Table 3), and 1.15 (95\% CI: 0.60, 2.21) for procedures in the two years before the child's conception (results not tabulated).

The effect estimates for childhood and parental radiological procedures in the CBT subtype analyses generally lacked precision (Table 4).

The overall OR for fetal in utero exposure (based on eight exposed cases and 14 exposed controls) was 1.71 (95\% CI: 0.69, 4.23) (results not tabulated). There were too few procedures carried out during pregnancy to investigate fetal exposure further.

\section{Discussion}

We found no evidence of positive associations between risk of CBT overall and diagnostic radiological procedures during childhood or in either parent in the period leading up to the child's conception. Weak evidence of an elevated risk was seen only for maternal procedures during pregnancy, and for childhood procedures and risk of high grade gliomas, but these results were based on small numbers and may be due to chance.

Unexpectedly, most of our results for childhood and maternal pre-pregnancy radiological procedures were suggestive of inverse associations with risk, and decreasing trends were observed for all procedures combined. An inverse association was also seen for childhood exposure in a small German cohort study that included 10 CBT cases [7]. However, two large cohort studies have found childhood CT scans are associated with increased brain tumor risk in childhood and early adulthood [5,6], and previous case-control studies of CBT have generally reported null or positive results [8-14]; therefore, we believe our results are unlikely to reflect true protective effects.

That we did not see increased risks associated with childhood CTs like those reported in two recent cohort studies [5,6] might be explained by the different calendar periods during which the majority of scans were done. As in the UK, CT scan doses reduced considerably in Australia from 2001 because of the more frequent use of age-specific dose settings [6]. For example, the current UK dose estimate for a CT brain scan on a 5-year old child is $28 \mathrm{mGy}$ - approximately one-half to onethird of the dose used before 2001 [5]. In our study, more than two-thirds of the CTs for children were done from 2001 onwards, while approximately two-thirds of CTs in the Australian cohort study [6], and almost all CTs from the UK study [5] were done before 2001. Thus, lower post-2001 dose levels may explain, at least in part, the lack of evidence of an increased risk in our study. In addition, the two cohort studies included tumors that developed in early adulthood.

The fact that most previous studies of radiological procedures during childhood have reported null or positive associations with CBT suggests the inverse associations we observed between use of radiological procedures and CBT may be due to bias or uncontrolled confounding. However, we 
have not identified any obvious candidate biases or confounders. Both cases and controls in our study had higher area-based SES scores than the average for Australia [18], but scores among participating controls were similar to those for cases. Further, although SES was related to study participation, it was not associated with radiological procedures for the child or the mother, and only marginally associated with area-based SES for the father. In addition, all analyses were adjusted for factors meeting the criteria for confounding. It is therefore unlikely that selection bias or confounding had a major impact on our results. If case parents had recalled exposures more fully than control parents, the ORs would tend to be inflated rather than reduced; therefore, it is unlikely that our findings are attributable to recall bias. Similarly, the use of a six-month lag period would not necessarily exclude confounding by indication. However, such an influence would lead to inflated rather than reduced ORs, and extending the lag period to 12 months and then five years did not change the observed associations; thus, confounding by indication is unlikely to explain our findings. Apart from chance, notwithstanding the low p-value, alternative explanations for these findings are difficult to identify.

Few mothers (eight cases and 14 controls) in our study underwent radiological procedures during pregnancy, so the effect estimate was imprecise: OR 1.71 (95\% CI 0.69, 4.23). A Swedish study [17] reported an elevated OR only for PNET: 1.88 (95\% CI: 0.92-3.83). The great majority of recent studies have reported null results [15]. Thus, this elevated OR may be due to recall bias if case mothers had better recall than control mothers when considering the causes of their child's disease. Recall bias is unlikely in the Swedish study, however, as data were extracted from medical records, but the estimates were based on only 16 exposed cases. In older studies where positive associations were seen for gestational procedures [20,21], more than $10 \%$ of mothers were exposed, and radiological doses were higher than those currently used.

Consistent with our results for radiological procedures in the parents prior to the child's conception, Shu et al. [11] found no association for paternal procedures, but some evidence of an inverse association for maternal procedures: OR 0.6 (95\% CI 0.3, 1.2) among mothers who had two or more $\mathrm{X}$-rays in the two years before conception. Bunin et al. [8] reported reduced ORs for paternal CT and risk of astrocytoma and PNET. These findings are imprecise and may be due to chance; alternative explanations are not clear.

Our study is only the second to investigate a variety of radiological procedures in fathers as well as mothers and children. We were also able to conduct preliminary analyses by procedure type, body area scanned and CBT subtype, although the power for these sub-analyses was limited, particularly for in utero exposure because of the relative infrequency with which radiological procedures are carried out during pregnancy [22]. 
Like all case-control studies involving self-report, our findings are subject to recall error. However, our questionnaires were designed to aid accurate recall, with explicit prompts regarding the procedure type, body part and timing; thus, we were able to reduce misclassification by excluding non-radiological procedures (e.g. ultrasounds/MRIs), those potentially related to the child's CBT diagnosis, and paternal procedures occurring after the child's conception.

In conclusion, we found no evidence that diagnostic radiological procedures during childhood including CTs - increase the risk of CBT, with the possible exception of high grade gliomas. This may be due to the relatively lower exposures from CTs done since 2001 or to currently unexplained bias in our results. Similarly, although there is little evidence of an increased risk of CBT with fetal in utero exposure to radiological procedures at current doses, more research is needed to establish the safety of more intense procedures like CT scans. 


\section{ACKNOWLEGEMENTS}

\section{Consortium Statement}

The Aus-CBT consortium conducted the study and the Telethon Institute for Child Health Research (TICHR), University of Western Australia, was the coordinating centre. Bruce Armstrong (Sydney School of Public Health, University of Sydney), Elizabeth Milne, Nicholas de Klerk, Carol Bower, Peter Dallas (TICHR), Frank van Bockxmeer (Royal Perth Hospital, University of WA), Rodney Scott and John Attia (University of Newcastle), Lin Fritschi (WA Institute for Medical Research), Lesley Ashton, Michelle Haber and Murray Norris (Children’s Cancer Institute Australia for Medical Research, Lowy Cancer Research Centre, UNSW), Margaret Miller (Edith Cowan University) and Judith Thompson (WA Cancer Registry) were the research investigators.

The authors acknowledge the contribution made by our clinical co-investigators who recruited and cared for study patients at each participating hospital: Nicholas Gottardo (Princess Margaret Hospital, TICHR); John Heath and Elizabeth Smibert (Royal Children’s Hospital, Melbourne); Peter Downie (Monash Medical Centre, Melbourne); Tim Hassall and Ross Pinkerton (Royal Children’s Hospital Brisbane); Maria Kirby (Women’s and Children’s Hospital, Adelaide); Stewart Kellie and Luciano dalla Pozza (Westmead Hospital); Frank Alvaro (John Hunter Hospital, Newcastle); Richard Cohn (Sydney Children’s Hospital) and John Daubenton (Royal Hobart Hospital).

The authors also acknowledge the Clinical Research Associates at each hospital, and the study coordinators: Jackie Mansour, Somer Dawson and Tamika Heiden.

Funding: The National Health and Medical Research Council (NHMRC) funded Aus-ALL (Grant number: 254539) and Aus-CBT (Grant number: 404089). Elizabeth Milne and Lin Fritschi were supported by NHMRC Fellowships and Helen Bailey was supported by NHMRC Post Graduate Scholarship 513934. Support for Rodney Scott was in part from NBN Children's Cancer Research Fund.

Conflict of Interest Disclosure: The authors declare that they have no conflict of interest. 


\section{REFERENCES}

1. Baldwin RT, Preston-Martin S (2004) Epidemiology of brain tumors in childhood--a review. Toxicol Appl Pharmacol 199:118-131.

2. International Agency for Research on Cancer (2012) A Review of Human Carcinogens:

Radiation: IARC Monographs on the Evaluation of Carcinogenic Risks to Humans Volume 100D. World Health Organization, Lyon.

3. Kleinerman RA (2006) Cancer risks following diagnostic and therapeutic radiation exposure in children. Pediatr Radiol 36 Suppl 2:121-125.

4. Robbins E (2008) Radiation risks from imaging studies in children with cancer. Pediatr Blood Cancer 51:453-457.

5. Pearce MS, Salotti JA, Little MP, McHugh K, Lee C, Kim KP, Howe NL, Ronckers CM, Rajaraman P, Craft AW, Parker L, de González AB (2012) Radiation exposure from CT scans in childhood and subsequent risk of leukaemia and brain tumours: a retrospective cohort study. Lancet 380:499-505.

6. Mathews JD, Forsythe AV, Brady Z, Butler MW, Goergen SK, Byrnes GB, Giles GG, Wallace AB, Anderson PR, Guiver TA, McGale P, Cain TM, Dowty JG, Bickerstaffe AC, Darby SC (2013) Cancer risk in 680000 people exposed to computed tomography scans in childhood or adolescence: data linkage study of 11 million Australians. Br Med J 346:f2360. doi: 2310.1136/bmj.f2360.

7. Hammer GP, Seidenbusch MC, Schneider K, Regulla DF, Zeeb H, Spix C, Blettner M (2009) A cohort study of childhood cancer incidence after postnatal diagnostic X-ray exposure. Radiat Res 171:504-512.

8. Bunin GR, Buckley JD, Boesel CP, Rorke LB, Meadows AT (1994) Risk factors for astrocytic glioma and primitive neuroectodermal tumor of the brain in young children: a report from the Children's Cancer Group. Cancer Epidemiol Biomarkers Prev 3:197-204.

9. Schuz J, Kaletsch U, Kaatsch P, Meinert R, Michaelis J (2001) Risk factors for pediatric tumors of the central nervous system: results from a German population-based case-control study. Med Pediatr Oncol 36:274-282.

10. Rajaraman P, Simpson J, Neta G, Berrington de Gonzalez A, Ansell P, Linet MS, Ron E, Roman E (2011) Early life exposure to diagnostic radiation and ultrasound scans and risk of childhood cancer: case-control study. Br Med J 342:d472. doi: http://dx.doi.org/410.1136/bmj.d1472.

11. Shu XO, Jin F, Linet MS, Zheng W, Clemens J, Mills J, Gao YT (1994) Diagnostic X-ray and ultrasound exposure and risk of childhood cancer. Br J Cancer 70:531-536. 
12. Cordier S, Iglesias MJ, Le Goaster C, Guyot MM, Mandereau L, Hemon D (1994) Incidence and risk factors for childhood brain tumors in the Ile de France. Int J Cancer 59:776-782.

13. Mellemkjaer L, Hasle H, Gridley G, Johansen C, Kjaer SK, Frederiksen K, Olsen JH (2006) Risk of cancer in children with the diagnosis immaturity at birth. Paediatr Perinat Epidemiol 20:231-237.

14. Khan S, Evans AA, Rorke-Adams L, Orjuela MA, Shiminski-Maher T, Bunin GR (2010) Head injury, diagnostic X-rays, and risk of medulloblastoma and primitive neuroectodermal tumor: a Children's Oncology Group study. Cancer Causes Control 21:1017-1023.

15. Schulze-Rath R, Hammer GP, Blettner M (2008) Are pre- or postnatal diagnostic X-rays a risk factor for childhood cancer? A systematic review. Radiat Environ Biophys 47:301-312.

16. Linet MS, Kim KP, Rajaraman P (2009) Children's exposure to diagnostic medical radiation and cancer risk: epidemiologic and dosimetric considerations. Pediatr Radiol 39 Suppl 1:S4-26.

17. Stålberg K, Haglund B, Axelsson O, Cnattingius S, Pfeifer S, Kieler H (2007) Prenatal X-ray exposure and childhood brain tumours: a population-based case-control study on tumour subtypes. Br J Cancer 97:1583-1587.

18. Milne E, Greenop KR, Bower C, Miller M, van Bockxmeer FM, Scott RJ, de Klerk NH, Ashton LJ, Gottardo NG, Armstrong BK (2012) Maternal use of folic acid and other supplements and risk of childhood brain tumors. Cancer Epidemiol Biomarkers Prev 21:1933-1941.

19. Bailey H, Milne E, de Klerk N, Fritschi L, Bower C, Attia J, Armstrong B (2010) Representativeness of child controls recruited by random digit dialing. Paediatr Perinat Epidemiol 24:293-302.

20. Macmahon B (1962) Prenatal x-ray exposure and childhood cancer. J Natl Cancer Inst 28:11731191.

21. Bithell JF, Stewart AM (1975) Pre-natal irradiation and childhood malignancy: a review of British data from the Oxford Survey. Br J Cancer 31:271-287.

22. Australian Radiation Protection and Nuclear Safety Agency (2008) Code of Practice: Radiation protection in the medical applications of ionizing radiation. Radiation protection series publication no. 14. http://www.arpansa.gov.au/pubs/rps/rps14.pdf. Accessed 1 May 2013. 
Table 1: Distribution of demographic and birth characteristics for Aus-CBT

\begin{tabular}{|c|c|c|c|c|c|c|}
\hline Variable & Category & Case $\mathrm{n}$ & $\begin{array}{l}\text { Case } \\
\%\end{array}$ & Control $\mathrm{n}$ & $\begin{array}{l}\text { Control } \\
\%\end{array}$ & $\begin{array}{l}\mathrm{N} \text { missing } \\
\text { (cases/ } \\
\text { controls) }\end{array}$ \\
\hline $\begin{array}{l}\text { Any written questionnaire } \\
\text { returned }\end{array}$ & & 306 & & 950 & & \\
\hline $\begin{array}{l}\text { Mother questionnaire } \\
\text { returned } \\
\text { (maternal \& filial exposures) }\end{array}$ & & 302 & & 941 & & \\
\hline $\begin{array}{l}\text { Father questionnaire } \\
\text { returned } \\
\text { (paternal exposures) }\end{array}$ & & 247 & & 801 & & \\
\hline \multirow[t]{2}{*}{ Child gender } & Female & 123 & 40.2 & 450 & 47.4 & \\
\hline & Male & 183 & 59.8 & 500 & 52.6 & \\
\hline \multirow[t]{4}{*}{ Child age group } & $0-1$ & 30 & 9.8 & 110 & 11.6 & \\
\hline & $2-4$ & 85 & 27.8 & 304 & 32.0 & \\
\hline & $5-9$ & 92 & 30.1 & 294 & 30.9 & \\
\hline & $10-14$ & 99 & 32.4 & 242 & 25.5 & \\
\hline \multirow[t]{5}{*}{ Child state residence $^{a}$} & NSW/ACT & 103 & 33.7 & 286 & 30.1 & \\
\hline & Vic/Tas & 86 & 28.1 & 251 & 26.4 & \\
\hline & $\mathrm{SA} / \mathrm{NT}$ & 19 & 6.2 & 78 & 8.2 & \\
\hline & WA & 42 & 13.7 & 114 & 12.0 & \\
\hline & Qld & 56 & 18.3 & 221 & 23.3 & \\
\hline \multirow[t]{3}{*}{ Child's birth year } & 1990-1998 & 86 & 28.1 & 229 & 24.1 & \\
\hline & $1998-2003$ & 127 & 41.5 & 472 & 49.7 & \\
\hline & $2004-2010$ & 93 & 30.4 & 249 & 26.2 & \\
\hline \multirow{3}{*}{$\begin{array}{l}\text { Year of diagnosis/ } \\
\text { Recruitment }\end{array}$} & $2005-2006$ & 109 & 35.6 & 418 & 44.0 & \\
\hline & $2007-2008$ & 101 & 33.0 & 271 & 28.5 & \\
\hline & $2009-2010$ & 96 & 31.4 & 261 & 27.5 & \\
\hline \multirow[t]{3}{*}{ Maternal age group } & $<25$ & 47 & 15.4 & 87 & 9.2 & $1 / 1$ \\
\hline & $25-34$ & 188 & 61.6 & 598 & 63.0 & \\
\hline & $35+$ & 70 & 23.0 & 264 & 27.8 & \\
\hline \multirow[t]{3}{*}{ Paternal age group } & $<25$ & 16 & 6.0 & 26 & 3.2 & $36 / 146$ \\
\hline & $25-34$ & 154 & 57.0 & 436 & 54.2 & \\
\hline & $35+$ & 100 & 37.0 & 342 & 42.5 & \\
\hline \multirow[t]{5}{*}{ Ethnic group ${ }^{\mathrm{b}}$} & European & 186 & 60.8 & 682 & 71.8 & \\
\hline & At least $50 \%$ & 76 & 24.8 & 176 & 18.5 & \\
\hline & European & & & & & \\
\hline & $\begin{array}{l}\text { At least 50\% non- } \\
\text { European }\end{array}$ & 12 & 3.9 & 30 & 3.2 & \\
\hline & Indeterminate & 32 & 10.5 & 62 & 6.5 & \\
\hline \multirow[t]{3}{*}{ Best Parental Education } & $\begin{array}{l}\text { Didn't complete } \\
\text { secondary school }\end{array}$ & 43 & 14.1 & 92 & 9.7 & \\
\hline & $\begin{array}{l}\text { Completed secondary } \\
\text { school and/or trade } \\
\text { qualification }\end{array}$ & 101 & 33.0 & 303 & 31.9 & \\
\hline & University/College & 162 & 52.9 & 555 & 58.4 & \\
\hline \multirow[t]{4}{*}{ Household Income } & Up to $\$ 40,000$ & 50 & 16.4 & 129 & 13.3 & $2 / 3$ \\
\hline & $\$ 40,001-\$ 70,000$ & 80 & 26.3 & 265 & 28.0 & \\
\hline & $\$ 70,001-\$ 100,000$ & 80 & 26.3 & 251 & 26.5 & \\
\hline & $>\$ 100,000$ & 94 & 31.0 & 302 & 31.9 & \\
\hline \multirow[t]{4}{*}{ Area-based SES ${ }^{\mathrm{c}}$} & Quartile 1 & 62 & 20.5 & 150 & 16.0 & $4 / 11$ \\
\hline & Quartile 2 & 68 & 22.5 & 213 & 22.7 & \\
\hline & Quartile 3 & 79 & 26.2 & 298 & 31.7 & \\
\hline & Quartile 4 & 93 & 30.8 & 278 & 29.6 & \\
\hline
\end{tabular}




\begin{tabular}{|c|c|c|c|c|c|c|}
\hline \multirow{3}{*}{ Birth order } & 1 & 139 & 45.6 & 400 & 42.1 & $1 / 1$ \\
\hline & 2 & 100 & 32.8 & 331 & 34.9 & \\
\hline & $3+$ & 66 & 21.6 & 216 & 23.0 & \\
\hline \multirow{2}{*}{$\begin{array}{l}\text { Maternal folic acid } \\
\text { supplementation } 1 \text { month } \\
\text { before pregnancy }\end{array}$} & No & 211 & 70.1 & 578 & 61.1 & $5 / 4$ \\
\hline & Yes & 90 & 29.9 & 368 & 38.9 & \\
\hline \multirow{2}{*}{$\begin{array}{l}\text { Maternal alcohol use } 12 \\
\text { months before pregnancy }\end{array}$} & No & 93 & 30.8 & 227 & 24.1 & $4 / 9$ \\
\hline & Yes & 209 & 69.2 & 714 & 75.9 & \\
\hline \multirow{2}{*}{$\begin{array}{l}\text { Maternal alcohol use during } \\
\text { pregnancy }\end{array}$} & No & 211 & 69.9 & 579 & 61.5 & $4 / 9$ \\
\hline & Yes & 91 & 31.1 & 362 & 38.5 & \\
\hline \multirow{2}{*}{$\begin{array}{l}\text { Paternal spirits consumption } \\
12 \text { months before pregnancy }\end{array}$} & No & 144 & 58.3 & 536 & 66.5 & $59 / 149$ \\
\hline & Yes & 103 & 41.7 & 265 & 33.1 & \\
\hline \multirow[t]{2}{*}{ Prematurity } & Term 37+ weeks & 272 & 89.2 & 869 & 92.0 & $1 / 5$ \\
\hline & Preterm $<37$ weeks & 33 & 10.8 & 76 & 8.0 & \\
\hline \multirow[t]{2}{*}{ Multiple birth } & No & 295 & 96.7 & 914 & 96.3 & $1 / 1$ \\
\hline & Yes & 10 & 3.3 & 35 & 3.7 & \\
\hline \multirow[t]{2}{*}{ Birth defect } & No & 289 & 95.4 & 903 & 96.0 & $3 / 9$ \\
\hline & Yes & 14 & 4.6 & 38 & 4.0 & \\
\hline
\end{tabular}

${ }^{\mathrm{a}}$ NSW: New South Wales; ACT: Australian Capital Territory; Vic: Victoria, Tas: Tasmania, SA:

South Australia, NT: Northern Territory, WA: Western Australia, Qld: Queensland.

${ }^{\mathrm{b}}$ Based on parent self-report; European: at least 3 European grandparents; 50\% European: 2

European grandparents; at least 50\% non-European: 2 non-European grandparents and ethnicity of 2 other grandparents unknown; indeterminate: no 2 grandparents of same ethnicity (i.e European or non-European) and 2+ grandparents of unknown ethnicity.

${ }^{\mathrm{c}} \mathrm{SES}=$ Area-of residence-based socio-economic status (Q4=highest SES, cut-points based on population data). 
Table 2: Childhood exposure to diagnostic radiological procedures and the risk of CBT

\begin{tabular}{llll}
\hline Exposure & n cases/controls & $\mathrm{OR}^{\mathrm{a}, \mathrm{b}}$ & $95 \% \mathrm{CI}$ \\
& $281 / 898$ & & \\
\hline No diagnostic radiological procedure & $179 / 523$ & 1.00 & Referent \\
Any diagnostic radiological procedure & $102 / 375$ & 0.66 & $0.48,0.90$ \\
No. of Procedures & & & \\
1 & $67 / 235$ & 0.70 & $0.50,0.99$ \\
$>1$ & $35 / 140$ & 0.59 & $0.38,0.93$ \\
$P$ for trend & & & 0.009 \\
Type of radiological procedure & & & \\
$\quad$ Any plain X-ray & $97 / 349$ & 0.68 & $0.49,0.93$ \\
$\quad$ Any CT scan & $13 / 35$ & 0.78 & $0.38,1.59$ \\
Site of body and type of procedure & & & \\
$\quad$ Any procedure to head (inc. dental) & $37 / 118$ & 0.68 & $0.42,1.08$ \\
$\quad$ Plain head X-ray & $27 / 93$ & 0.61 & $0.36,1.03$ \\
CT scan to head & $12 / 31$ & 0.83 & $0.40,1.75$ \\
Any plain chest X-ray & $27 / 112$ & 0.67 & $0.42,1.08$ \\
Any whole body X-ray & $3 / 7$ & 1.03 & $0.25,4.25$ \\
\hline
\end{tabular}

${ }^{\text {a }}$ Adjusted for matching variables, maternal age group, child's birth year, maternal alcohol consumption during pregnancy, maternal folic acid use before pregnancy.

${ }^{\mathrm{b}}$ Radiological procedure within 6 months of the census date were excluded from the analysis.

Abbreviations: CBT: childhood brain tumors; OR: Odds ratio; CI: Confidence interval; CT: computed tomography 
Table 3: Parental exposure to diagnostic radiological procedures at any time before the index pregnancy and the risk of CBT

\begin{tabular}{|c|c|c|c|c|c|c|}
\hline & \multicolumn{3}{|c|}{ Maternal } & \multicolumn{3}{|c|}{ Paternal } \\
\hline & $\begin{array}{l}\text { n cases/ } \\
\text { controls } \\
(293 / 929) \\
\end{array}$ & $\mathrm{OR}^{\mathrm{a}}$ & $95 \% \mathrm{CI}$ & $\begin{array}{l}\text { n cases } \\
\text { /controls } \\
(243 / 789) \\
\end{array}$ & $\mathrm{OR}^{\mathrm{b}}$ & $95 \% \mathrm{CI}$ \\
\hline No diagnostic radiological procedure $^{c}$ & $228 / 642$ & 1.00 & Referent & $178 / 548$ & 1.00 & Referent \\
\hline $\begin{array}{l}\text { Any diagnostic radiological procedure } \\
\text { No. of procedures }\end{array}$ & $65 / 287$ & 0.69 & $0.50,0.94$ & $65 / 241$ & 0.89 & $0.64,1.24$ \\
\hline 1 & $44 / 178$ & 0.72 & $0.49,1.04$ & $49 / 165$ & 0.95 & $0.66,1.39$ \\
\hline $\begin{array}{l}>1 \\
p \text { trend }\end{array}$ & $21 / 109$ & 0.64 & $\begin{array}{l}0.39,1.05 \\
0.02\end{array}$ & $16 / 76$ & 0.74 & $\begin{array}{l}0.41,1.32 \\
0.35\end{array}$ \\
\hline Type of radiological procedure & & & & & & \\
\hline Any plain $\mathrm{x}$-ray & $54 / 231$ & 0.72 & $0.51,1.01$ & $52 / 209$ & 0.81 & $0.57,1.17$ \\
\hline Any CT scan & $8 / 47$ & 0.51 & $0.24,1.12$ & $11 / 29$ & 1.27 & $0.60,2.70$ \\
\hline Any barium study & $6 / 42$ & 0.48 & $0.20,1.16$ & $8 / 29$ & 0.99 & $0.43,2.27$ \\
\hline Any IVP & $9 / 30$ & 0.82 & $0.38,1.79$ & $3 / 10$ & 1.00 & $0.27,3.76$ \\
\hline Site of body & & & & & & \\
\hline Any abdominal X-ray & $23 / 94$ & 0.76 & $0.47,1.24$ & $19 / 82$ & 0.78 & $0.46,1.35$ \\
\hline $\begin{array}{l}\text { Any X-ray or CT of lower back, } \\
\text { pelvis or hips }\end{array}$ & $41 / 200$ & 0.62 & $0.43,0.91$ & $49 / 180$ & 0.91 & $0.62,1.32$ \\
\hline Any kidney X-rays & $13 / 40$ & 0.95 & $0.49,1.84$ & $4 / 19$ & 0.62 & $0.20,1.89$ \\
\hline
\end{tabular}

${ }^{a}$ Adjusted for matching variables, maternal age, child's ethnicity, year of diagnosis, maternal alcohol consumption 12 months before pregnancy, maternal folic acid use 1 month before pregnancy.

b Adjusted for matching variables, paternal age, child's ethnicity, child's birth year, paternal alcoholic spirit consumption 12 months before pregnancy, area-based SES quartiles.

${ }^{\mathrm{c}}$ Reference group for all maternal analyses was no radiological procedures at any time before or during the pregnancy, for paternal analysis no radiological procedures at any time before the pregnancy. 
Table 4: Childhood and parental diagnostic radiological procedure by CBT subtype

\begin{tabular}{|c|c|c|c|c|c|c|c|c|c|c|}
\hline & \multirow[b]{2}{*}{$\begin{array}{l}\text { Any } \\
\text { procedure? }\end{array}$} & \multicolumn{3}{|c|}{$\begin{array}{l}\text { Childhood } \\
\text { (at least } 6 \text { months before diagnosis) }\end{array}$} & \multicolumn{3}{|c|}{ Mother pre-pregnancy } & \multicolumn{3}{|c|}{ Father pre-pregnancy } \\
\hline & & $\begin{array}{l}\text { n cases/ } \\
\text { controls }\end{array}$ & $\mathrm{OR}^{\mathrm{a}}$ & $95 \% \mathrm{CI}$ & $\begin{array}{l}\text { n cases/ } \\
\text { controls }\end{array}$ & $\mathrm{OR}^{\mathrm{b}}$ & $95 \% \mathrm{CI}$ & $\begin{array}{l}\text { n cases/ } \\
\text { controls }\end{array}$ & $\mathrm{OR}^{\mathrm{C}}$ & $95 \% \mathrm{CI}$ \\
\hline \multirow[t]{2}{*}{ Low grade gliomas } & No & $78 / 523$ & 1.00 & Referent & $109 / 642$ & 1.00 & Referent & $87 / 548$ & 1.00 & Referent \\
\hline & Yes & $53 / 375$ & 0.82 & $0.54,1.26$ & $30 / 287$ & 0.65 & $0.42,1.00$ & $32 / 241$ & 0.90 & $0.57,1.41$ \\
\hline \multirow[t]{2}{*}{ High grade gliomas } & No & $12 / 523$ & 1.00 & Referent & 21/642 & 1.00 & Referent & $16 / 548$ & 1.00 & Referent \\
\hline & Yes & $13 / 375$ & 1.71 & $0.68,4.30$ & $5 / 287$ & 0.63 & $0.23,1.74$ & $6 / 241$ & 1.12 & $0.40,3.08$ \\
\hline \multirow[t]{2}{*}{ Embryonal tumors $^{\mathrm{d}}$} & No & $49 / 523$ & 1.00 & Referent & $51 / 642$ & 1.00 & Referent & $41 / 548$ & 1.00 & Referent \\
\hline & Yes & $18 / 375$ & 0.39 & $0.21,0.72$ & $17 / 287$ & 0.83 & $0.47,1.50$ & $14 / 241$ & 0.83 & $0.43,1.58$ \\
\hline \multirow[t]{2}{*}{ Germ cell tumors } & No & $11 / 523$ & 1.00 & Referent & $16 / 642$ & 1.00 & Referent & $9 / 548$ & 1.00 & Referent \\
\hline & Yes & 9/375 & 0.38 & $0.14,1.04$ & 4/287 & 0.72 & $0.21,2.43$ & $2 / 241$ & 0.45 & $0.08,2.47$ \\
\hline \multirow[t]{2}{*}{ Ependymomas } & No & $14 / 523$ & 1.00 & Referent & $17 / 642$ & 1.00 & Referent & $13 / 548$ & 1.00 & Referent \\
\hline & Yes & $6 / 375$ & 0.81 & $0.28,2.35$ & $5 / 287$ & 0.65 & $0.23,1.83$ & $7 / 241$ & 1.41 & $0.52,3.80$ \\
\hline
\end{tabular}

${ }^{a}$ ORs adjusted for matching variables, ethnicity, child's birth year, maternal age, maternal folic acid use 1 month before pregnancy, maternal alcohol consumption during pregnancy.

${ }^{\mathrm{b}}$ ORs adjusted for matching variables, ethnicity, year of diagnosis/recruitment group, maternal age, maternal folic acid use 1 month before pregnancy, maternal alcohol consumption 12 months before pregnancy.

${ }^{c}$ ORs adjusted for matching variables, ethnicity, child's birth year, paternal age, paternal alcoholic spirit consumption 12 months before the pregnancy, area-based SES quartiles.

d Embryonal tumors comprises: medulloblastomas, primitive neuroectodermal tumors, atypical teratoid rhabdoid tumors.

Abbreviations: CBT: childhood brain tumors; OR: Odds ratio; CI: Confidence Interval 